\title{
1 Chromatographic Separation of Germanium and Arsenic 2 for the Production of High Purity ${ }^{77} \mathrm{As}$
}

3 Matthew D. Gott ${ }^{1}$, Anthony J. DeGraffenreid ${ }^{1}$, Yutian Feng ${ }^{1}$, Michael D. Phipps ${ }^{1}$, Donald E.

4 Wycoff $^{1}$, Mary F. Embree ${ }^{2}$, Cathy S. Cutler ${ }^{2, \beta}$, Alan R. Ketring ${ }^{2}$, Silvia S. Jurisson ${ }^{1 *}$

$5 \quad{ }^{1}$ Department of Chemistry, University of Missouri, Columbia, MO 65211

$6 \quad{ }^{2}$ University of Missouri Research Reactor Center, Columbia, MO 65211

7

8

9

10

11

12

13

14

15

16

17

18

19

20

21

22

23 Correspondence to: Silvia S. Jurisson, Department of Chemistry, University of Missouri,

24 Columbia, MO 65211; jurissons@ missouri.edu; 573-882-2107; 573-882-2754 (fax)

25

26

27

28

${ }^{\beta}$ Current address: Medical Isotope Research \& Production Program (MIRP), Collier-Accelerator Department, Brookhaven National Laboratory, Upton, NY 11973 


\section{Abstract}

A simple column chromatographic method was developed to isolate ${ }^{77} \mathrm{As}(94 \pm 6 \%(\mathrm{EtOH} / \mathrm{HCl})$; $74 \pm 11(\mathrm{MeOH})$ ) from germanium for potential use in radioimmunotherapy. The separation of arsenic from germanium was based on their relative affinities for different chromatographic materials in aqueous and organic environments. Using an organic or mixed mobile phase, germanium was selectively retained on a silica gel column as germanate, while arsenic was eluted from the column as arsenate. Subsequently, enriched ${ }^{76} \mathrm{Ge}(98 \pm 2)$ was recovered for reuse by elution with aqueous solution (neutral to basic). Greater than $98 \%$ radiolabeling yield of a ${ }^{77}$ As-trithiol was observed from methanol separated $\left[{ }^{77}\right.$ As]arsenate [17].

Key Words: Ge/As separation; Ge/As distribution coefficient; column chromatography; high specific activity arsenic-77

\section{Introduction}

Radionuclides are widely used in nuclear medicine and represent powerful tools in both diagnosis and therapy of disease [1-3]. Reactor-produced radionuclides are often of low specific activity because they originate from $(\mathrm{n}, \gamma)$ reactions on the same element; for example, ${ }^{153} \mathrm{Sm}$ is produced by the reaction ${ }^{152} \mathrm{Sm}(\mathrm{n}, \gamma){ }^{153} \mathrm{Sm}$ with the product not separable from the target, and only $1-2 \%$ of the atoms are converted to ${ }^{153} \mathrm{Sm}$. High specific activity radionuclides can be made indirectly in a reactor by producing the parent radionuclide via the $(n, \gamma)$ reaction, which then beta $\left(\beta^{-}\right)$decays to the radionuclide of interest (a different element) and that can be chemically separated from the target material. One such radionuclide is ${ }^{77} \mathrm{As}\left(\mathrm{t}_{1 / 2}=38.8 \mathrm{~h}, \beta^{-}, 100 \%, \mathrm{E}_{\beta} \max \right.$ $=0.683 \mathrm{MeV})$, which is available from the decay of ${ }^{77} \mathrm{Ge}\left(\mathrm{t}_{1 / 2}=11.30 \mathrm{~h}, \beta^{-}, 100 \%, \mathrm{E}_{\beta} \max =2.7\right.$ $\mathrm{MeV}) ;{ }^{77} \mathrm{Ge}$ is produced via the ${ }^{76} \mathrm{Ge}(\mathrm{n}, \gamma){ }^{77} \mathrm{Ge}$ reaction in a reactor, and then $\beta^{-}$decays to ${ }^{77}$ As. Arsenic-77 is a beta-emitting radionuclide of interest for therapeutic applications as a matched pair to the diagnostic, positron-emitting radionuclide ${ }^{72} \mathrm{As}\left(\mathrm{t}_{1 / 2}=26.0 \mathrm{~h}, \beta^{+}, 88 \%, \mathrm{EC}, 12 \%\right)$. Together these two radioisotopes provide an excellent diagnostic/therapeutic pair. The relatively long half-lives of both ${ }^{72} \mathrm{As}$ and ${ }^{77} \mathrm{As}$ make them amenable for radiolabeling antibodies and proteins, which require more time (up to several days) to localize to their targeted tissues, thus enabling a wider range of applications [4]. The chemistry of As is versatile allowing for the development of new potential radiopharmaceuticals. However, As radionuclides have limited availability, which is hindered by issues with the separation methods available to produce a high purity product.

Many methods to isolate As from Ge have been reported including solvent extraction [5, 6], distillation [7, 8], ion exchange [8-10], solid phase extraction [11-13], and thin layer chromatography [14]. The solvent extraction methods reported often involve several labor intensive steps, including back extractions, and are not readily adapted for high activity separations requiring remote handling. Distillation methods require heating, some to high temperature $\left(1105{ }^{\circ} \mathrm{C}[7]\right)$, which increases sample processing time and may require further 
radioarsenic purification [8]. Chromatographic methods involving ion exchange or solid phase adsorption provide an efficient, robust purification method more readily adapted to automated, remote handling required with high levels of radioactivity. Many of the current literature methods involve the use of strong acids (e.g., >8 $\mathrm{M} \mathrm{HNO}_{3}, \mathrm{HF}, \mathrm{HCl}$ ) in the separation process, which are undesirable for radionuclides that will be used for synthesizing radiopharmaceuticals [8-12]. Chakravarty [13] reported a two-column separation for high purity radioarsenic from a $\mathrm{GeO}_{2}$ target using nanocrystalline titania. This method requires the synthesis and strict quality control of the nanocrystalline titania, which is not commercially available. We report a simple, single column Ge/As separation method under mild conditions in an effort to make high purity, high specific activity ${ }^{77}$ As more readily available. The method minimizes handling of the target material, reduction in operator dose, and use of mild reagents throughout the separation process.

\section{Experimental}

\subsection{Materials}

All reagents and solvents were purchased from Alfa Aesar (Ward Hill, MA) and Fisher Scientific (Pittsburg, PA). Enriched ${ }^{76} \mathrm{GeO}_{2}(96.2 \%$ or $98.5 \%$ enrichment) was purchased from Trace Sciences International (Richmond Hill, ON, Canada). Analytical grade silica gel, SilicAR, was purchased from Mallinckrodt (St. Louis, MO). Commercial $60 \AA$ silica gel was purchased from Acros Organics (Geel, Belgium). Acidic alumina was purchased from Fisher Scientific. Zirconium oxide resin (HZO-01) and poly-prep columns (0.8 cm ID; $10 \mathrm{~mL}$ reservoir) were purchased from Bio-Rad Corporation (Hercules, CA). All materials were used as received without further purification. All water used was purified on-site (deionized water from a Millipore system to greater than $18 \mathrm{M} \Omega \mathrm{cm})$.

\subsection{Radionuclide Production and Stock Radiotracer Solutions}

Caution! Germanium-77 and ${ }^{76,77}$ As are radioactive and all work involving these radionuclides was carried out in approved laboratories following the appropriate radiation safety procedures. Germanium-77, used as a Ge tracer in column and batch studies, was produced at the University of Missouri Research Reactor (MURR) via the ${ }^{76} \mathrm{Ge}(\mathrm{n}, \gamma){ }^{77} \mathrm{Ge}$ reaction of a quartz encapsulated

${ }^{76} \mathrm{GeO}_{2}$ target (3-5 mg). High specific activity ${ }^{77} \mathrm{As}$ (370-555 MBq (10-15 mCi) was available from the decay of ${ }^{77} \mathrm{Ge}$. Carrier-added ${ }^{76} \mathrm{As}$ was produced at MURR via the ${ }^{75} \mathrm{As}(\mathrm{n}, \gamma){ }^{76} \mathrm{As}$ reaction from ${ }^{\text {nat }} \mathrm{As}_{2} \mathrm{O}_{3}$ ( ${ }^{\text {nat }} \mathrm{As}$ is $100 \%{ }^{75} \mathrm{As} ; 5-10 \mathrm{mg}$ ). Table 1 lists the various radionuclides and their nuclear properties.

Table 1. Nuclear properties of germanium and arsenic isotopes of interest. [15]

\begin{tabular}{llll}
\hline Radionuclide & Half-life & $\mathbf{E}_{\mathbf{m a x}} \boldsymbol{\beta}^{-}(\mathbf{M e V})$ & Gamma emissions in keV (abundances) \\
\hline${ }^{76} \mathrm{As}$ & $26.3 \mathrm{~h}$ & 2.962 & $559.1(45.0 \%)$ \\
${ }^{77} \mathrm{As}$ & $38.8 \mathrm{~h}$ & 0.683 & $239(1.59 \%)$ \\
${ }^{77} \mathbf{G e}$ & $11.3 \mathrm{~h}$ & 2.702 & $211(30.0 \%), 215.5(27.9 \%), 264.5(53.3 \%)$ \\
\hline
\end{tabular}




\subsection{1 ${ }^{77}$ Ge Stock Solutions.}

The irradiated ${ }^{76} \mathrm{GeO}_{2}$ target was dissolved in $450 \mu \mathrm{L}$ of $1 \mathrm{M} \mathrm{NaOH}(0.1 \mathrm{M} \mathrm{NaOH}$ is sufficient $)$ with gentle heat $\left(35-45^{\circ} \mathrm{C}\right)$ and stirring over 20 minutes and then treated further, as described below, for either batch/column studies with methanolic eluent or for column studies with ethanolic eluents.

\subsubsection{Stock Solution for Batch Studies and Column Studies Using Methanolic Eluents.}

Following dissolution, the target was acidified to $\mathrm{pH} 4-5$ with $1 \mathrm{M} \mathrm{HCl}(0.1 \mathrm{M} \mathrm{HCl}$ for $0.1 \mathrm{M}$ $\mathrm{NaOH}$ dissolution), and then $100 \mu \mathrm{L}$ of $30 \% \mathrm{H}_{2} \mathrm{O}_{2}$ was added to ensure the sample was fully oxidized; the solution was then heated at $60^{\circ} \mathrm{C}$ to destroy the excess hydrogen peroxide. This solution was used as a stock solution for all batch studies and column chromatography studies using methanol and water as eluents.

\subsubsection{Stock Solution for Column Studies Using Ethanolic Eluents.}

Following target dissolution, the $\mathrm{pH}$ of the target was acidified to approximately $\mathrm{pH} 1-2$ instead of $\mathrm{pH} 4-5$ and then $100 \mu \mathrm{L}$ of $30 \% \mathrm{H}_{2} \mathrm{O}_{2}$ was added to ensure the sample was fully oxidized; the solution was then heated at $60^{\circ} \mathrm{C}$ to destroy the excess hydrogen peroxide. A $100 \mu \mathrm{L}$ aliquot of this solution was diluted to a total volume of $500 \mu \mathrm{L}$ using $0.01 \mathrm{M} \mathrm{HCl}$ to maintain a pH of 2 . This diluted solution was used for all of the column chromatographic studies using an eluent containing ethanol.

\subsection{2 ${ }^{76}$ As Stock Solution.}

The irradiated ${ }^{\text {nat }} \mathrm{As}_{2} \mathrm{O}_{3}$ sample was directly dissolved in $500 \mu \mathrm{L}$ of $1 \mathrm{M} \mathrm{NaHCO}_{3}$.

\subsection{Instrumental Analysis}

Radiochemical assays for ${ }^{76,77} \mathrm{As}$ and ${ }^{77} \mathrm{Ge}$ related to the batch studies and methanol-based column chromatographic studies were determined by $\gamma$-ray spectroscopy using a Canberra Model GC2018S HPGe detector system with a relative efficiency of $20 \%$ at $1.33 \mathrm{MeV}$. Spectral analyses were performed using a Canberra Model 9660 analyzer. All samples were counted for 900 seconds and decay corrected to the time correlating to either the end of contact time for the batch studies or the first column wash for the column studies. The detector dead time was less than $10 \%$ for all samples.

Radiochemical assays for ${ }^{77} \mathrm{As}$ and ${ }^{77} \mathrm{Ge}$ related to the ethanol and mixed-solvent column chromatographic studies were determined by $\gamma$-ray spectroscopy on an Ortec Model GEM20-70 HPGe detector system with a relative efficiency of $23 \%$ at $1.33 \mathrm{MeV}$. Spectral analyses were performed using a Canberra DSA LX analyzer. All samples were counted for 600 seconds and decay corrected to the time correlating to count time of the original Ge/As solution. The detector dead time was less than $10 \%$ for all samples. 


\subsection{Batch Studies: Determination of Optimum Chromatographic Media}

Several media were evaluated in room temperature batch studies for their ability to separate Ge and As following a previously published method [16]. The removal of Ge and As from varying $\mathrm{pH}$ (1-13) solutions was measured by mixing $50 \mathrm{mg}$ of each substrate (silica, acidic alumina, and zirconium oxide) with $1.5 \mathrm{~mL}$ of a ${ }^{77} \mathrm{Ge}$ - or ${ }^{76} \mathrm{As}$-spiked solution $(154 \mathrm{kBq}(4.17 \mu \mathrm{Ci})$ and 81 $\mathrm{kBq}(2.19 \mu \mathrm{Ci})$ per sample, respectively); each solution was adjusted to the desired $\mathrm{pH}$ using either $0.1 \mathrm{M} \mathrm{HCl}$ or $\mathrm{NaOH}, 1-2 \mu \mathrm{L}$ of the spiked solution was added, and the $\mathrm{pH}$ retested. The solution $\mathrm{pH}$ was determined using $\mathrm{pH}$ strips due to the radioactivity present in samples. The liquid-solid system was mixed by vortex for 2 minutes and immediately centrifuged for 2 minutes at $7500 \mathrm{rpm}$. Two $500 \mu \mathrm{L}$ aliquots of the contacted solution $\left(\mathrm{A}_{\mathrm{s}}\right)$ were transferred into clean $1 \mathrm{~mL}$ HDPE vials. Additionally, a $500 \mu \mathrm{L}$ aliquot of the original uncontacted solution $\left(\mathrm{A}_{0}\right)$ was transferred to a clean $1 \mathrm{~mL}$ HDPE vial as the standard. The activity in each vial was determined by $\gamma$-ray spectroscopy and the distribution ratio, $\mathrm{K}_{\mathrm{d}}$, calculated by the following formulation:

$K_{d}=\frac{\left(A_{0}-A_{S}\right)}{A_{s}} * \frac{V}{m}$

$A_{0}$ is the original Ge or As activity in the aqueous solution. $A_{s}$ is the Ge or As activity remaining in solution following contact with the resin. $\left(\mathrm{A}_{0}-\mathrm{A}_{\mathrm{s}}\right)$ is the amount of activity adsorbed by the resin. The volume $(\mathrm{V})$ of the aqueous solution is measured in milliliters and the mass $(\mathrm{m})$ is measured in grams resulting in a distribution ratio unit of $\mathrm{mL} / \mathrm{g}$. The experimental errors are reported as a function of the standard deviation.

\subsection{Silica Column Chromatography Studies}

\subsubsection{Methanol Eluent}

A simplified method using only the silica gel column was evaluated. A small, preparative column packed with a $1 \mathrm{~mL}$ bed volume of silica gel was conditioned with methanol $(\sim 10 \mathrm{~mL})$. A $50 \mu \mathrm{L}$ aliquot of the ${ }^{77} \mathrm{Ge} /{ }^{77}$ As stock solution of known activities was added to the top of the column followed by twenty $1-\mathrm{mL}$ methanol elutions. The column was then stripped with three 1-mL DI $\mathrm{H}_{2} \mathrm{O}$ and four 1-mL $0.01 \mathrm{M} \mathrm{NaOH}$ elutions (Table 2). A $500 \mu \mathrm{L}$ aliquot of each fraction eluted was counted by $\gamma$-ray spectroscopy.

\subsubsection{HCl:Ethanol Mixed Solvent Eluent}

Various ratios (Table 3) of $\mathrm{HCl}$ :ethanol were evaluated for arsenic elution from the column while maintaining germanium retention. A small, preparative column was wet-packed with a 1 $\mathrm{mL}$ bed volume of silica gel $(\sim 510 \mathrm{mg})$ slurried with ethanol and was conditioned with the mobile phase of interest $\left(\sim 10\right.$ bed volumes). A $50 \mu \mathrm{L}$ aliquot of the ${ }^{77} \mathrm{Ge} /{ }^{77}$ As stock solution, 
which had been oxidized and $\mathrm{pH}$ adjusted to 1.5-2.5, was added to the top of the column followed by elution with the mobile phase of interest $(4 \times 1 \mathrm{~mL})$. All fractions were assayed by $\gamma$-ray spectroscopy along with an aliquot of the load sample.

\subsection{Synthesis of $\left[{ }^{77}\right.$ As](4-ethyl-2,6,7-trithia-1-arsabicyclo[2.2.2]octane)}

The synthesis of this $\left[{ }^{77} \mathrm{As}\right]$-labeled trithiol from methanol separated $\left[{ }^{77} \mathrm{As}\right.$ ]arsenate has been reported [17]. Briefly, aqueous ammonium mercaptoacetate (25 mM), and 2-ethyl-2(mercaptomethyl)propane-1,3-dithiol (trithiol ligand; $15 \mu \mathrm{M}$ in absolute ethanol) were combined in a reaction vial. To this solution was added an aliquot of the $\left[{ }^{77}\right.$ As]arsenate in DI water (the methanol had been removed at $50{ }^{\circ} \mathrm{C}$ and then DI water added). The reaction mixture was heated at $60{ }^{\circ} \mathrm{C}$ for $30 \mathrm{~min}$. RP-HPLC analysis as previously reported gave $>98 \%$ radiochemical yield.

\section{Results and Discussion}

Radiochemical separations can be challenging because of the very large mass difference (often $10^{6}$ or greater) between the desired radionuclide produced and the irradiated target. Additionally, the target material is often recovered because it is highly enriched in the particular isotope that generated the desired radionuclide, and therefore quite precious (costly). A separation was developed to isolate no carrier added (nca) ${ }^{77}$ As and recover the highly enriched $(96-99 \%){ }^{76} \mathrm{Ge}$ target for reuse. Of the methods reported for the separation of nca radioarsenic from Ge targets, most include a step to ensure that the radioarsenic is in oxidation state +3 . Since nca As(III) oxidizes to nca As(V) within minutes, a separation was developed to isolate nca As(V). Maki and Murakami [14] reported a silica gel thin-layer chromatographic (TLC) method to separate ${ }^{77} \mathrm{As}(\mathrm{III})$ and ${ }^{77} \mathrm{As}(\mathrm{V})$ from its $\mathrm{GeO}_{2}$ target with methanol and $\mathrm{HCl}$ as the eluent. Caletka and Kotas [12] reported that at acid concentrations $>8 \mathrm{M},{ }^{68} \mathrm{Ge}$ was retained on silica gel columns while ${ }^{68} \mathrm{Ga}$ and other radionuclides (including ${ }^{77} \mathrm{As}$ ) were eluted. Bokhari et al. [10] reported a column chromatographic method using hydrous zirconium oxide (HZO) to selectively adsorb Ge under basic conditions $(0.1 \mathrm{M} \mathrm{NaOH})$ while $~ 90 \%$ of the radioarsenic passed through the $\mathrm{HZO}$, most likely as As(V). The prior studies suggested that silica gel might allow a simple, straightforward separation for ${ }^{77} \mathrm{As}$ from its enriched ${ }^{76} \mathrm{Ge}$ target. With the aim of incorporating the ${ }^{77} \mathrm{As}$ into bifunctional chelates following purification, $>8 \mathrm{M}$ acid was not considered an optimal separation medium. Thus, several chromatographic media were investigated with eluents over the entire $\mathrm{pH}$ range and with methanol, and finally with ethanol to make the system more biocompatible. An additional consideration in radiochemical separations is minimization of the eluent volume required to isolate the desired radionuclide so that subsequent handling prior to use is minimized.

\subsection{Determination of Optimum Chromatographic Media}

Inorganic media such as acidic alumina, silica gel and hydrous zirconium oxide (HZO-01) are often considered for use in radiochemical separations because they are more resistant to radiation damage than organic-based resins. These media were evaluated for their ability to retain arsenate 
and germanate with equilibrium distribution ratios acquired as a function of $\mathrm{pH}(1-13)$. Distribution ratios were determined for $\mathrm{As}$ and $\mathrm{Ge}$ at each $\mathrm{pH}$ and in methanol using the batch method, and are reported as mean values and their calculated experimental errors. Separation factors were calculated for each condition from the distribution ratios. For acidic alumina, a maximum ${ }^{77} \mathrm{Ge} /{ }^{76} \mathrm{As}$ separation factor of $9 \pm 1$ was observed at $\mathrm{pH} 11$; this value is somewhat low and would require a large column and elution volumes or risk tailing of one species into the other (Figure 1). For silica gel, a substantial ${ }^{77} \mathrm{Ge} /{ }^{76} \mathrm{As}$ separation factor of $82 \pm 16$ was observed using methanol as the eluent, which could be used to recover the bulk of the Ge target material while eluting arsenate with methanol (Figure 2). Germanate adsorbed strongly to the silica gel in methanol and had no retention under any aqueous conditions, while arsenate showed little affinity under the conditions evaluated. A usable ${ }^{76} \mathrm{As} /{ }^{77} \mathrm{Ge}$ separation factor of $19 \pm 8$ was observed using HZO-01 and methanol as the eluent, which could allow for the isolation of arsenate from Ge (Figure 3). Arsenate was retained by HZO-01 in methanol and had little affinity in either very high or very low $\mathrm{pH}(\mathrm{pH} \leq 1$ or $\geq 11)$ aqueous conditions, while germanate had little affinity in methanol and greater affinity under high $\mathrm{pH}$ aqueous conditions.

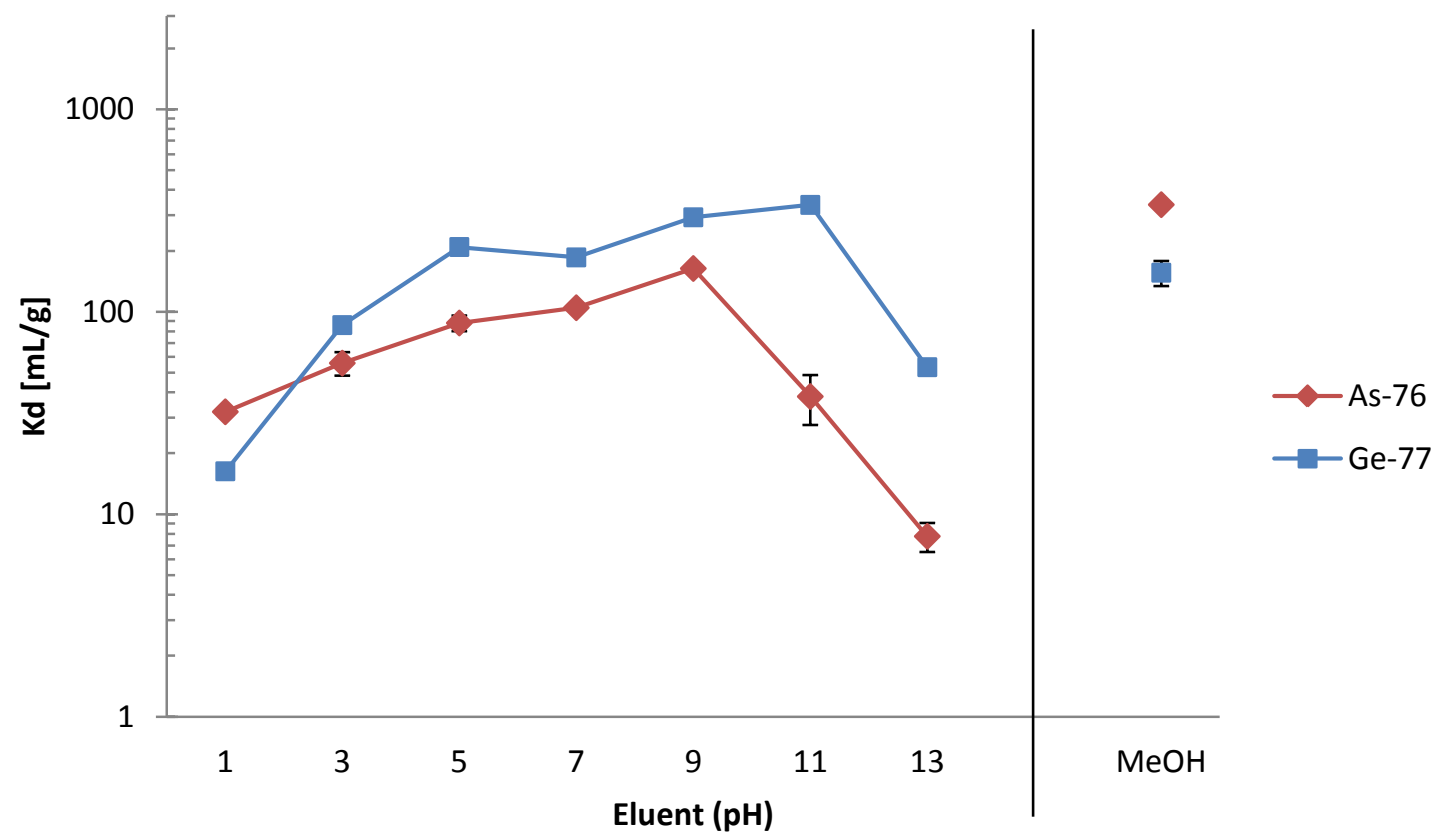

219 Figure 1. Distribution coefficient for arsenate and germanate on acidic alumina over the $\mathrm{pH}$ range 1-13 and in methanol. ( $n=6$; error bars included and determined as a function of the 221 standard deviation) 


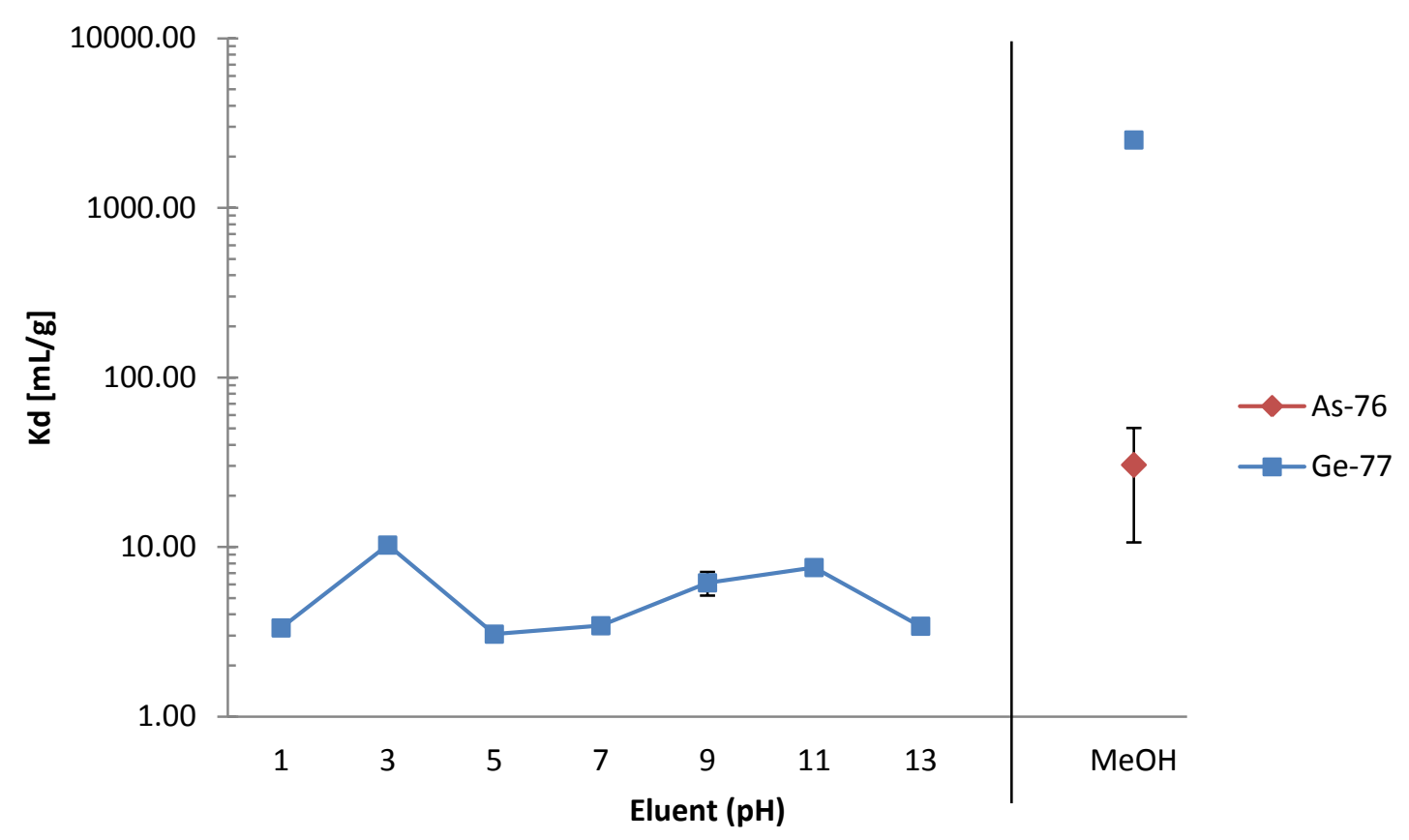

225 Figure 2. Distribution coefficient for arsenate and germanate on silica over the pH range 1-13 or 226 in methanol. Under aqueous conditions, all distribution coefficients for aresenate were $<1$. $(n=6$;

227 error bars included and determined as a function of the standard deviation)

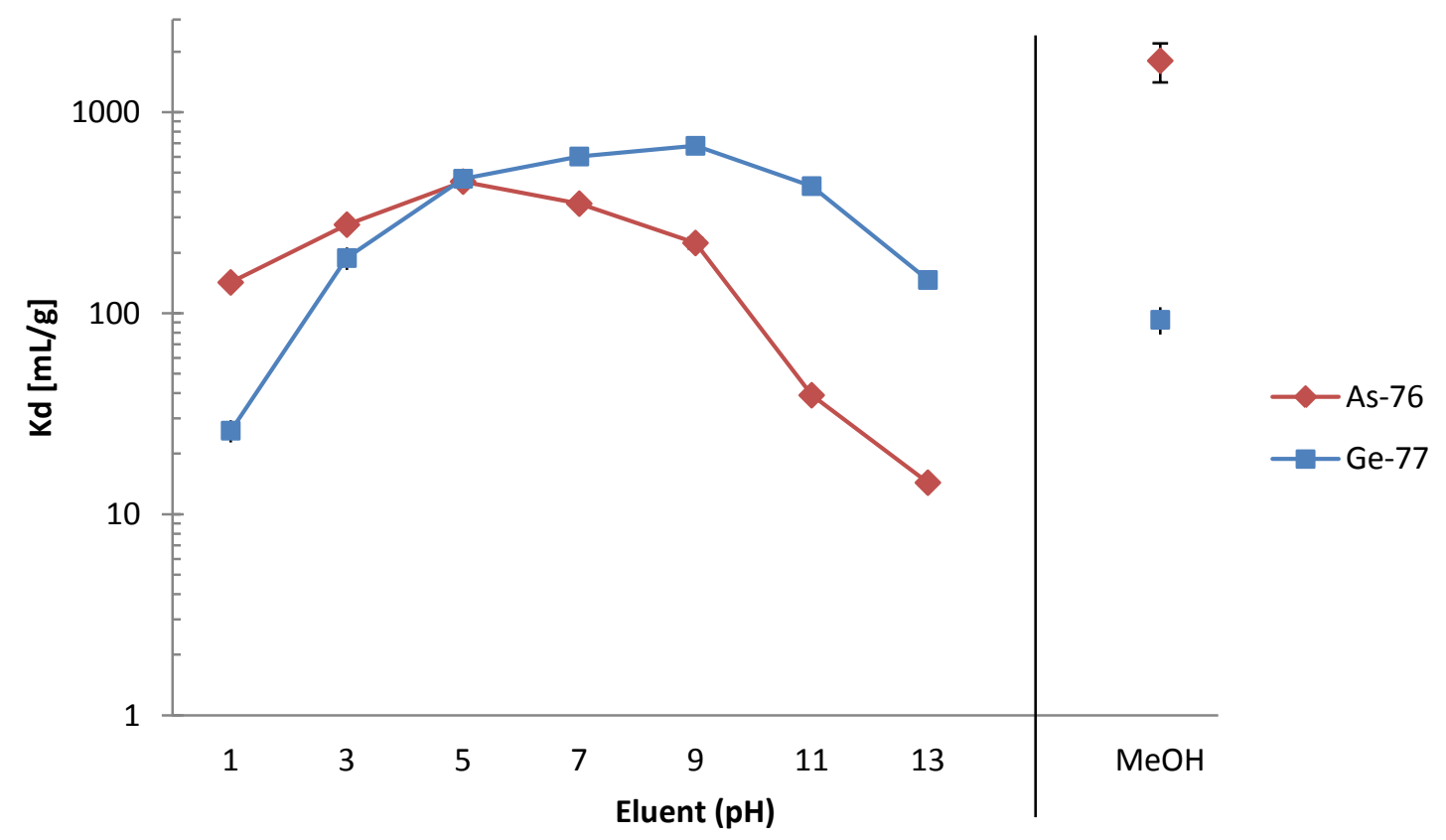

229 Figure 3. Distribution coefficient for arsenate and germanate on hydrous zirconium oxide (HZO) 230 over the $\mathrm{pH}$ range $1-13$ or in methanol. ( $\mathrm{n}=6$; error bars included and determined as a function of 231 the standard deviation) 


\begin{tabular}{ccc}
\hline $\begin{array}{c}\text { Radionuclide } \\
\text { Mobile Phase }\end{array}$ & $\begin{array}{c}{ }^{77} \text { As Elution }(\%) \\
\text { Methanol }\end{array}$ & $\begin{array}{c}{ }^{77} \text { Ge Recovery (\%) } \\
\text { DI Water and 0.01 M NaOH }\end{array}$ \\
\hline & 79 & 95.4 \\
Average (\% $\mathbf{\text { SD) }}$ & 82.4 & 99 \\
\hline
\end{tabular}

\subsection{Tandem Column Assembly with Methanol and Base as Eluents}

To apply the distribution coefficients in a practical application, a tandem column assembly using silica gel and HZO-01 resin was evaluated. The distribution coefficients indicated the silica gel should trap the bulk Ge, while the HZO-01 should trap the As when methanol was the eluent; any Ge breakthrough from the silica gel should pass through the HZO-01 leaving a high purity ${ }^{77}$ As product behind. Additionally, any residual Ge on the HZO-01 column would be trapped using a $\mathrm{pH} 11$ solution, while eluting the As based on their relative distribution coefficients (430 \pm 20 and $39 \pm 1$, respectively). Arsenic adsorbed more strongly to the HZO-01 resin than the distribution coefficients suggested. No As elution was observed using a $\mathrm{pH} 11$ solution and required a $\mathrm{pH} 13$ solution to elute the trapped arsenate. Even under these highly basic conditions, a large portion of the As remained on the column. Although the As elution sample was free of detectable Ge, significant loss of As was observed using the tandem column assembly.

\subsection{Silica Column(s) with Methanolic Eluents}

The distribution coefficients and high separation factor suggested a facile separation of As and Ge using methanol. A reasonable recovery of the ${ }^{77}$ As $(74 \pm 11 \%)$ eluted in $4 \mathrm{~mL}$ of methanol with very little, if any, ${ }^{77} \mathrm{Ge}$ breakthrough $(0.09 \% \pm 0.08)$ observed. A newly opened bottle of methanol resulted in lower recovery ( $60 \%$ vs $\sim 80 \%$ ) likely due to the water content (methanol is quite hygroscopic). Efficient recovery of $\mathrm{Ge}$ is critical due to the high cost associated with the enriched ${ }^{76} \mathrm{GeO}_{2}$ starting material, which is recycled for reuse. Recovery of greater than $86 \%$ of the ${ }^{77} \mathrm{Ge}$ in $5 \mathrm{~mL}$ of water mitigates this concern; $98 \%$ recovery is observed with $0.01 \mathrm{M} \mathrm{NaOH}$ following the water elution (Table 2). The elution profile is shown in Figure 4. The large loss of ${ }^{77}$ As likely resulted from the precipitation of $\mathrm{Ge}$ during $\mathrm{pH}$ adjustment with $\mathrm{HCl}$. This has been visibly observed at the macroscopic scale and quite possibly occurs at the microscale, though not visibly. As the Ge precipitates, it traps the tracer As in the process; this was further indicated by the co-elution of a larger portion of As with the Ge when the eluent was changed to water.

Table 2. Recovery of ${ }^{76,77} \mathrm{Ge}$ following ${ }^{77}$ As elution with $\mathrm{MeOH}$ with three 1-mL $\mathrm{DI} \mathrm{H}_{2} \mathrm{O}$ and four 1-mL $0.01 \mathrm{M} \mathrm{NaOH}$ elutions.

\footnotetext{
Freshly opened bottle of methanol used for this study; not as wet.
} 


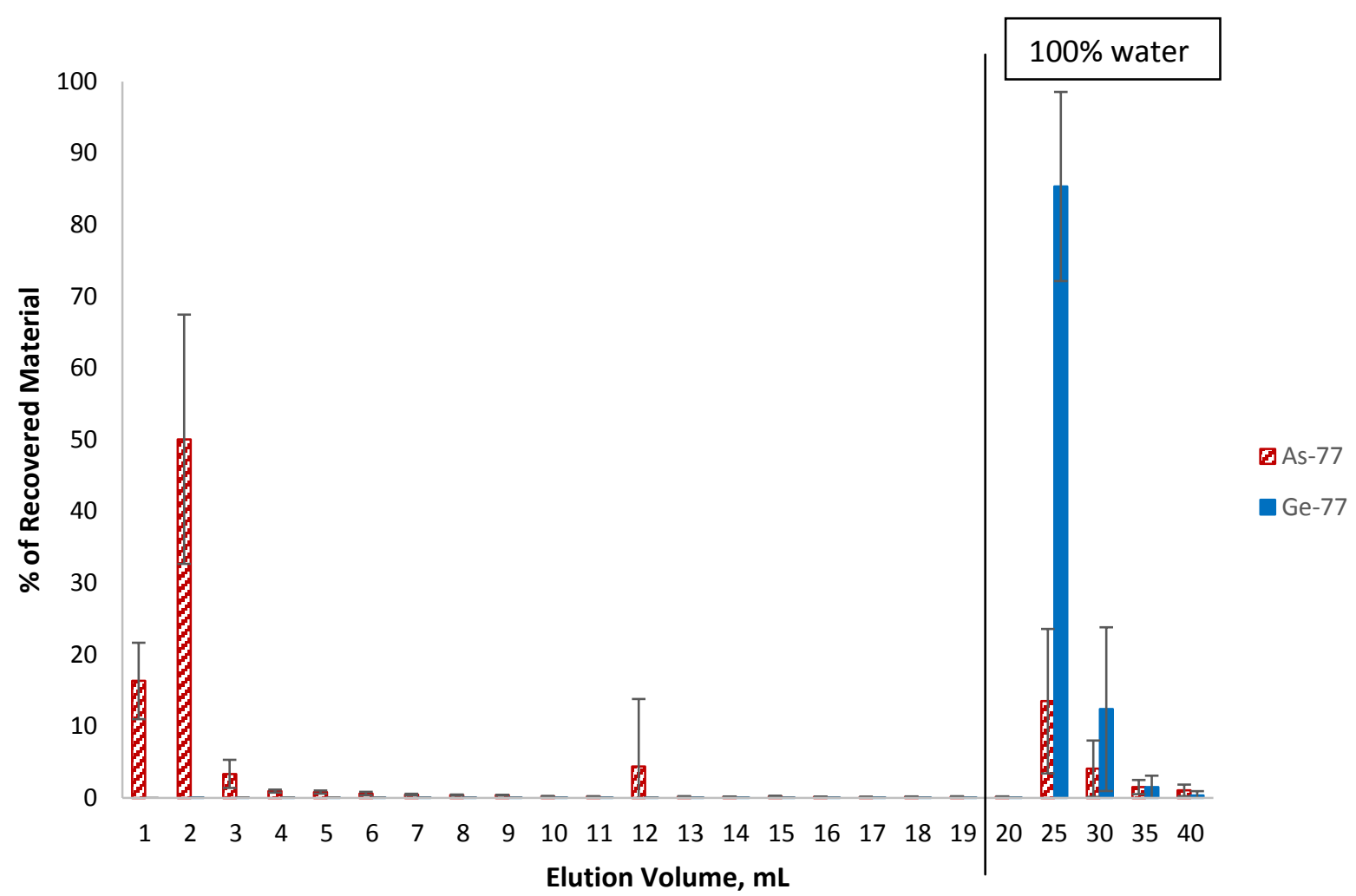

Figure 4. Elution profile for ${ }^{77} \mathrm{Ge} /{ }^{77}$ As separation. The eluent was changed from methanol to deionized water at $20 \mathrm{~mL}$ to recover the Ge target material. ( $\mathrm{n}=6$; error bars included)

If As was simply lost to silica adsorption, the recovery on a second column should have been approximately $1 / 3$, as observed with the first column. To further investigate this loss of As, the arsenic-containing fractions were passed through a second silica gel column. Interestingly, greater than $80 \%$ of the As loaded onto the second silica gel column was recovered, while germanium was reduced to non-detectable levels. This result further supports loss related to Ge precipitation.

\subsection{Evaluation of the Dissolution and Solution Preparation Method}

The ${ }^{76} \mathrm{GeO}_{2}$ targets were dissolved in base $(\mathrm{NaOH})$ and acidified prior to loading onto the silica gel columns. To evaluate the effect of acid used for acidification to $\mathrm{pH} 4-5, \mathrm{HCl}, \mathrm{HNO}_{3}$, and $\mathrm{H}_{3} \mathrm{PO}_{4}$ were compared. The results are shown in Figures 5-7. Each data set was normalized to the percentage of recovered material to eliminate variations resulting from overall recovery with each mobile phase. The $\mathrm{HCl}$-adjusted sample exhibited very little Ge breakthrough in the first $10 \mathrm{~mL}(0.6 \%)$. However a sizable percentage $(12.7 \%)$ of the ${ }^{77}$ As co-eluted with the ${ }^{77} \mathrm{Ge}$, suggesting it was trapped within a $\mathrm{Ge}$ precipitate. Use of $\mathrm{HNO}_{3}$ resulted in less Ge breakthrough $(0.04 \%$ in the first $10 \mathrm{~mL})$, but a larger portion of ${ }^{77} \mathrm{As}$ was trapped within the Ge precipitate (25.7\%), suggesting more of a Ge precipitate with $\mathrm{HNO}_{3}$. Finally, $\mathrm{H}_{3} \mathrm{PO}_{4}$ was unique compared to use of the other two acids as a much higher percentage of ${ }^{77} \mathrm{As}$ was recovered quickly $(67.6 \%$ in $1 \mathrm{~mL})$ but Ge breakthrough was more substantial $(0.3 \%$ with the first $\mathrm{mL}$ and $6.1 \%$ in the 
284 second $\mathrm{mL})$. Additionally, very little ${ }^{77}$ As co-eluted with Ge (0.4\%) suggesting less Ge 285 precipitation occurred with this system. Overall $\mathrm{HCl}$ outperformed $\mathrm{HNO}_{3}$ and $\mathrm{H}_{3} \mathrm{PO}_{4}$ since a 286 large portion of the Ge was successfully retained on the column without sacrificing As recovery.

287

288

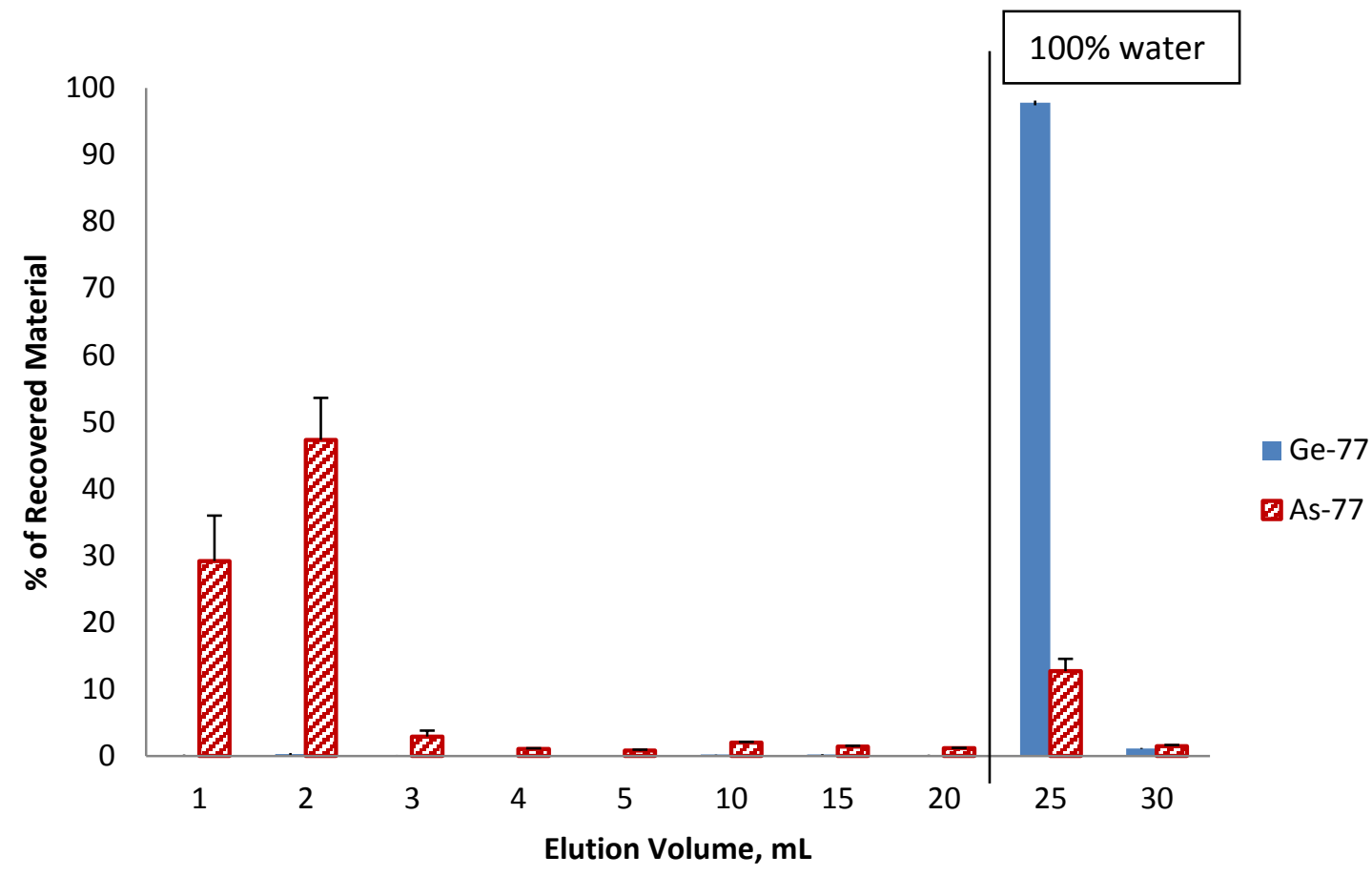

290 Figure 5. Elution profile for $\mathrm{HCl}$ adjusted $\mathrm{Ge}$ separation. ( $\mathrm{n}=3$; error bars included) 


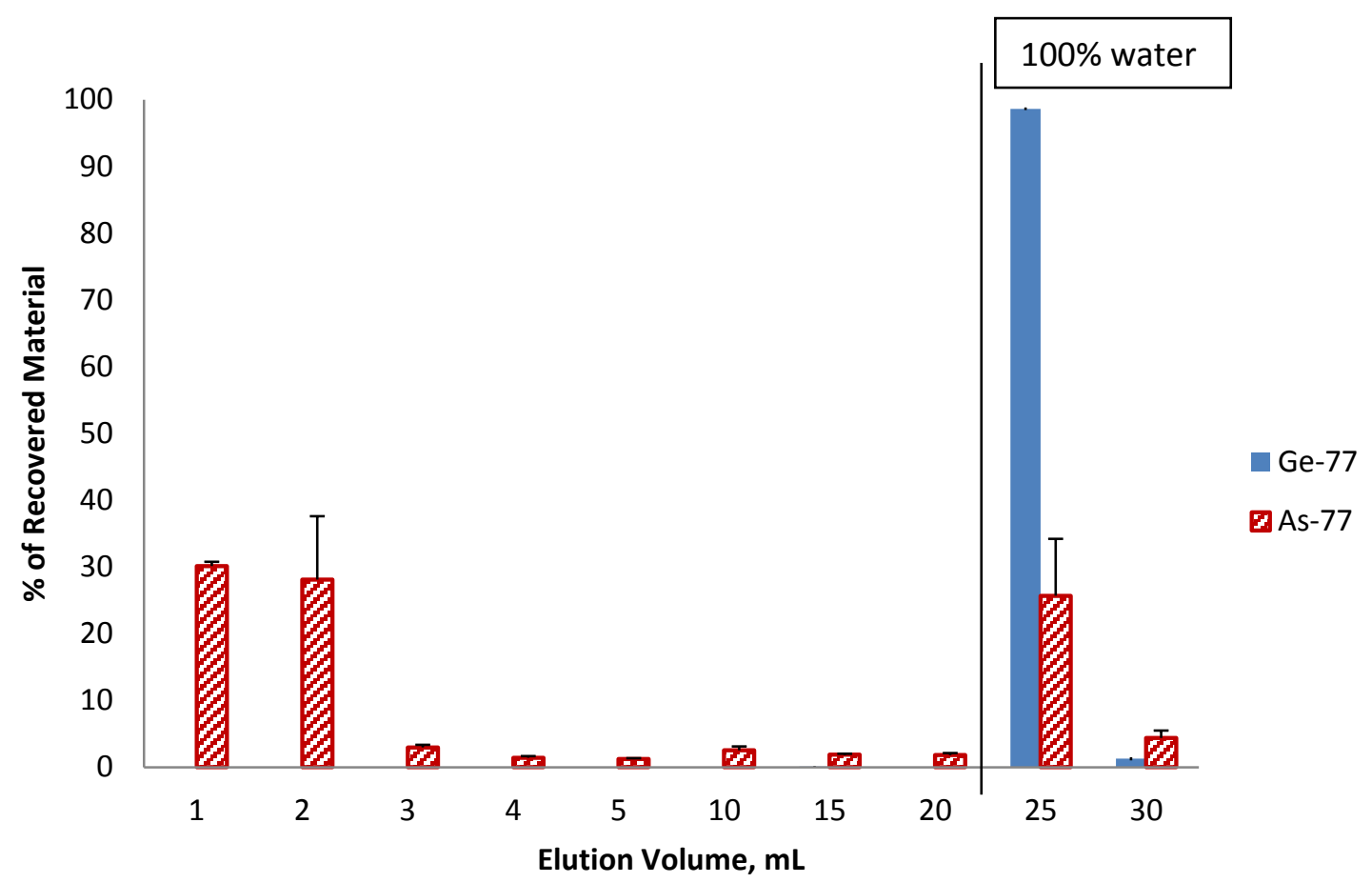

Figure 6. Elution profile for $\mathrm{HNO}_{3}$ adjusted Ge separation. (n=3; error bars included)

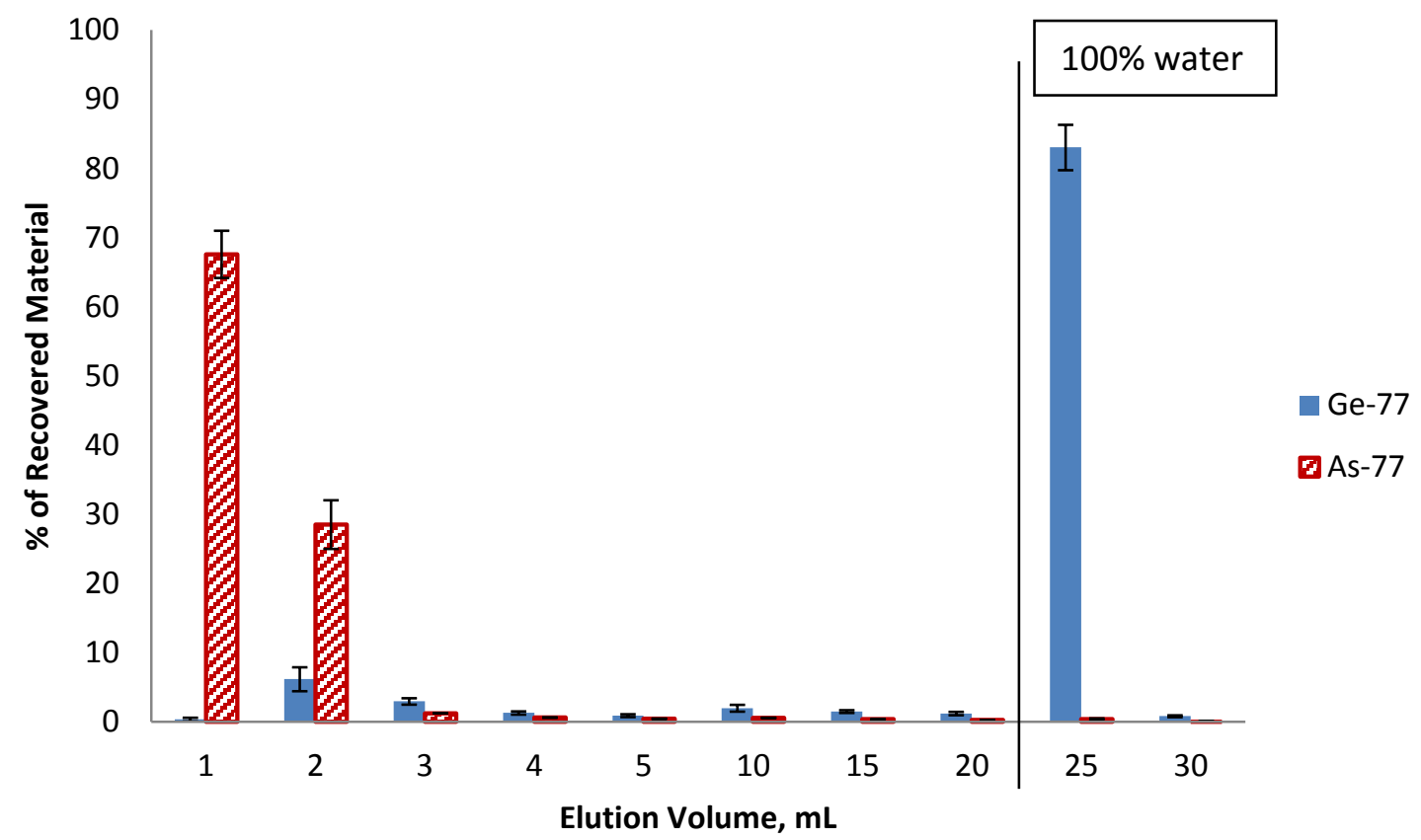

Figure 7. Elution profile for $\mathrm{H}_{3} \mathrm{PO}_{4}$ adjusted Ge separation. ( $\mathrm{n}=3$; error bars included)

\subsection{Column Chromatography Studies with an HCl:Ethanol Mixed Solvent System}

300
To make the process biocompatible, ethanol was evaluated as a substitute for methanol. Arsenic was more strongly retained by the silica gel with ethanol as the eluent. Studies varying the 
loading conditions were performed and it was observed that acidifying the loading solution resulted in lower breakthrough of germanium. The $\mathrm{pH}$ of the loading solution was lowered from 4-5 to $1-2$, which resulted in a recovery of $7 \pm 2 \%$ of the ${ }^{77}$ As eluting in ethanol with no detectable breakthrough of $\mathrm{Ge}$. Additional studies were performed with $\mathrm{HCl}$ incorporated directly into the ethanol or with a mixed aqueous/ethanol mobile phase. In the mixed aqueous $\mathrm{HCl} /$ ethanol mobile phases the addition of water had a substantial impact on the recovery of As. Adding too much water resulted in breakthrough of Ge. This effect was counteracted by using a higher acid concentration in lower volumes. Similar recovery of ${ }^{77}$ As was observed when concentrated $\mathrm{HCl}$ was directly added to ethanol, $91 \pm 4 \%$ (Tables 3 and 4; note that the two different lots of enriched ${ }^{76} \mathrm{GeO}_{2}$ obtained from Trace Sciences International unexpectedly behaved quite differently). The HCl:ethanol mobile phase showed excellent separation of ${ }^{77} \mathrm{As}$ and recovery of $\mathrm{Ge}$ especially when water content was minimized.

Table 3. Recovery of ${ }^{77} \mathrm{As}$ and breakthrough of ${ }^{77} \mathrm{Ge}$ using a $96.2 \%$ enriched ${ }^{76} \mathrm{GeO}_{2}$ target $(\mathrm{n}=$ 3 unless noted by $*$, where $n=4$ ).

\begin{tabular}{|c|c|c|}
\hline Mobile Phase & ${ }^{77}$ As Recovery (\%) & ${ }^{77}$ Ge Breakthrough (\%) \\
\hline $\mathrm{MeOH}^{*}$ & $74 \pm 11$ & None detected (ND) \\
\hline Absolute EtOH & $7 \pm 2$ & ND \\
\hline 12 M HCl:EtOH (1:120) & $73 \pm 6$ & ND \\
\hline 12 M HCl:EtOH (1:1200) & $80 \pm 2$ & ND \\
\hline 5 M HCl:EtOH (2:1) & $87 \pm 8$ & ND \\
\hline 1 M HCl:EtOH (2:1)* & $95 \pm 3$ & $1 \pm 1$ \\
\hline $0.1 \mathrm{M}$ HCl:EtOH (2:1)* & $86 \pm 7$ & $13 \pm 6$ \\
\hline 0.1 M HCl:EtOH (1:1)* & $81 \pm 4$ & $5 \pm 3$ \\
\hline 0.1 M HCl:EtOH (1:10)* & $76 \pm 3$ & ND \\
\hline 0.01 M HCl:EtOH (1:1) & $73 \pm 2$ & $6 \pm 7$ \\
\hline 0.01 M HCl:EtOH (1:10)* & $36 \pm 5$ & $0 \pm 0$ \\
\hline
\end{tabular}

*When a new bottle of methanol was used as the eluent, only $61.4 \%$ Ge recovery was observed versus $\sim 80 \%$ recovery from one that had been opened previously (i.e., contained more water).

Table 4. Recovery of ${ }^{77}$ As and breakthrough of ${ }^{77} \mathrm{Ge}$ using a $98.5 \%$ enriched ${ }^{76} \mathrm{GeO}_{2}$ target $(\mathrm{n}=$ 5).

\begin{tabular}{ccc}
\hline Mobile Phase & ${ }^{77}$ As Recovery (\%) & ${ }^{77}$ Ge Breakthrough (\%) \\
\hline Absolute EtOH & $3 \pm 1$ & ND \\
12 M HCl:EtOH (1:1200) & $91 \pm 4$ & ND \\
0.1 M HCl:EtOH (1:10) & $94 \pm 6$ & ND \\
\hline
\end{tabular}




\subsection{Radiolabeling Study}

The utility of the $\left[{ }^{77}\right.$ As]arsenate separated by this method is demonstrated by radiolabeling studies. A trithiol ligand, namely 2-ethyl-2-(mercaptomethyl)propane-1,3-dithiol, was carried out as previously reported [17] in $>98 \%$ yield of the ${ }^{77}$ As-trithiol product (Figure 8).

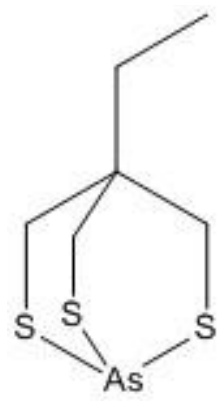

Figure 8. Structure of $\left[{ }^{77} \mathrm{As}\right]-$ trithiol, namely 4-ethyl-2,6,7-trithia-1-arsabicyclo[2.2.2]octane.

\section{Conclusions}

The availability of high purity radioarsenic, such as ${ }^{72} \mathrm{As}$ and ${ }^{77} \mathrm{As}$, would provide a longer-lived, non-metallic radionuclide pair for radioimmunoimaging and radioimmunotherapy. The versatile chemistry of arsenic would enable the development of potential new radiopharmaceuticals. A quick, robust method for the separation of nca ${ }^{77} \mathrm{As}$ from its $\mathrm{GeO}_{2}$ target material was developed to increase the availability of high purity ${ }^{77} \mathrm{As}$, with the enriched ${ }^{76} \mathrm{Ge}$ starting material easily recovered for reuse.

Distribution coefficient studies showed germanium has a strong affinity for silica gel using methanol as the mobile phase while arsenic had limited affinity. Isolation of $74 \mathrm{MBq}(2 \mathrm{mCi})$ of ${ }^{77} \mathrm{As}$ was consistently eluted free of $\mathrm{Ge}$ when $210 \mathrm{MBq}(5.7 \mathrm{mCi})$ of ${ }^{77} \mathrm{As} /{ }^{76,77} \mathrm{Ge}$ was loaded onto $520 \mathrm{mg}$ of silica gel. Fine tuning the column chromatographic method based on the observed distribution coefficients resulted in the optimal separation method using a single silica gel column and a mixed mobile phase with a $1: 10$ ratio of $0.1 \mathrm{M} \mathrm{HCl}$ and ethanol; this system recovered $94 \pm 6 \%$ of the arsenic in a small volume with no detectible germanium. Likewise a high recovery rate $(91 \pm 4 \%)$ was observed using a single silica gel column and a mixed mobile phase with a $0.01 \mathrm{M} \mathrm{HCl}$ solution prepared directly in ethanol using concentrated $\mathrm{HCl}$. Germanium was easily recovered from the column by elution with water. With the 1:10 ratio of $0.1 \mathrm{M} \mathrm{HCl}$ :EtOH eluent using $520 \mathrm{mg}$ of silica gel, $74 \mathrm{MBq}(2.0 \mathrm{mCi})$ of ${ }^{77} \mathrm{As}$ is consistently eluted free of Ge when $89 \mathrm{MBq}(2.4 \mathrm{mCi})$ of ${ }^{77} \mathrm{As} /{ }^{76,77} \mathrm{Ge}$ was loaded. This method gives a higher percentage recovery of ${ }^{77}$ As than does the methanol eluent (83\% versus $74 \%$ ).

Separation of large mass targets containing higher activities is required to demonstrate the utility of this method for routine production. If scale-up is successful, the separated ${ }^{77}$ As would be available for use as a tracer for medical, toxicological, and environmental studies, which is the ultimate goal of this project. 


\section{Acknowledgments}

The authors acknowledge support from the Department of Energy, Office of Basic Sciences, Isotope Research Program under grants DE-SC0003851 and DE-SC0010283. Additional trainee support was provided from the National Science Foundation under IGERT award DGE-0965983 (M.D. Gott) and the National Institutes of Health under NIBIB Training Grant 5 T32-EB004822 (A.J. DeGraffenreid).

\section{References}

[1] G.B. Saha; Chapter 4 Production of Radionuclides, Fundamentals of Nuclear Pharmacy, $3^{\text {rd }}$ Ed. Springer: New York, 2010; 49-66.

[2] M. Page; Tumor Targeting in Cancer Therapy, Humanan Press: Totowa, NJ, 2002; 257-275.

[3] S.M. Qaim; The present and future of medical radionuclide production, Radiochim. Acta 2012 100, 635-651.

[4] T.K. Nayak, M.W. Brechbiel; Radioimmunoimaging with Longer-Lived Positron-Emitting Radionuclides: Potential and Challenges, Bioconjugate Chem. 2009 20, 825-841.

[5] S. Chattopadhyay, S. Pal, K.V. Vimalnath, M.K. Das; A versatile technique for radiochemical separation of medically useful no-carrier-added (nca) radioarsenic from irradiated germanium oxide targets, Appl. Radiat. Isot. 2007 65, 1202-1207.

[6] M.M. Shehata, B. Scholten, I. Spahn, H.H. Coenen, S.M. Qaim; Separation of radioarsenic from irradiated germanium oxide targets for the production of ${ }^{71}$ As and ${ }^{72} \mathrm{As}$, J. Radioanal. Nucl. Chem. 2011 287, 435-442.

[7] V. Tolmachev, H. Lundqvist; Separation of arsenic from germanium oxide targets by dry distillation, J. Radioanal. Nucl. Chem. 2001 247(1), 61-66.

[8] M. Jahn, V. Radchenko, D. Filosofov, H. Hausner, M. Eisenhut, F. Rosch, M. Jennewein; Separation and purification of no-carrier-added arsenic from bulk amounts of germanium for use in radiopharmaceutical labeling, Radiochim. Acta $\mathbf{2 0 1 0}$ 98, 807-812.

[9] R. Guin, S.K. Das, S.K. Saha; Separation of carrier-free arsenic from germanium, J. Radioanal. Nucl. Chem. 1998 227(1-2), 181-182. 
384 [10] T.H. Bokhari, A. Mushtaq, I.U. Khan; Separation of no-carrier-added arsenic-77 from 385 neutron irradiated germanium, Radiochim. Acta 2009 97, 503-506.

386 [11] M. Jennewein, S.M. Qaim, A. Hermanne, M. Jahn, E. Tsyganov, N. Slavine, S. Seliounine, 387 P.A. Antich, P.V. Kulkarni, P.E. Thorpe, R.P. Mason, F. Rosch; A new method for 388 radiochemical separation of arsenic from irradiated germanium oxide, Appl. Radiat. Isot. 2005 $38963,343-351$.

390 [12] R. Caletka, P. Kotas; Separation of Germanium from some elements by adsorption on silica 391 gel, J. Radioanal. Nucl. Chem. 1974 21(2), 349-353.

392 [13] R. Chakravarty, R. Ram, K.C. Jagdeesan, M. Venkatesh, A. Dash, Polymer Embedded 393 Nanocrystalline Titania: A New Generation Sorbent for the Separation of ${ }^{77}$ As from Ge for 394 Biomedical Applications, Chromatographia 2011 74, 531-540.

395 [14] Y. Maki, Y. Murakami; The separation of arsenic-77 in a carrier-free state from the parent 396 nuclide germanium-77 by a thin-layer chromatographic method, J. Radioanal. Nucl. Chem. 1974 397 22(1), 5-12.

398 [15] National Nuclear Data Center: http://www.nndc.bnl.gov

399 [16] M.D. Gott, B.D. Ballard, L.N. Redman, J.R. Maassen, W.A. Taylor, J.W. Engle, F.M. 400 Nortier, E.R. Birnbaum, K.D. John, D.S. Wilbur, C.S. Cutler, A.R. Ketring, S.S. Jurisson, M.E. 401 Fassbender; Radiochemical Study of Re/W Adsorption Behavior on a Strongly Basic Anion 402 Exchange Resin, Radiochim. Acta 2014 102(4), 325-332.

403 [17] A.J. DeGraffenreid, Y. Feng, C.L. Barnes, A.R. Ketring, C.S. Cutler, S.S. Jurisson; Trithiols 404 and their Arsenic Compounds for Potential Use in Diagnostic and Therapeutic

405 Radiopharmaceuticals, Nucl. Med. Biol. 2016 (available online as in press;

406 http://dx.doi.org/10.1016/j.nucmedbio.2016.01.005) 